\title{
The role of copper in the manufacture of Finnish Emmental cheese
}

\author{
L. Mato Rodriguez, ${ }^{*}$ T. Ritvanen, $†$ V. Joutsjoki, $\neq$ J. Rekonen, ${ }^{\star} \S$ and T. Alatossava*1 \\ *Department of Food and Environmental Sciences, Division of Food Technology, Viikki campus, University of Helsinki, PO Box 66 , \\ FIN-00014 Helsinki, Finland \\ †Finnish Food Safety Authority Evira, Chemistry and Toxicology Unit, Mustialankatu 3, FIN-00790 Helsinki, Finland \\ $\ddagger$ MTT Agrifood Research Finland, Biotechnology and Food Research, FIN-31600, Jokioinen, Finland \\ $\S$ Valio Ltd. Research and Develop Unit, PO Box 30, FIN-00039 Valio, Helsinki, Finland
}

\section{ABSTRACT}

The effects of added copper in the manufacture of Finnish Emmental cheese were studied. Consequently, cheeses were produced with or without the copper supplement and a facultative heterofermentative strain, Lactobacillus rhamnosus Lc705, which is currently utilized as a protective culture in large-scale manufacture in Finland. Cheeses were examined at 1, 7, 30, 60, and $90 \mathrm{~d}$ from the microbiological, chemical, and sensory points of view. Organic acid production was affected by the presence of copper in the cheeses. The addition of copper to cheesemilk increased the level of primary proteolysis and slowed secondary proteolysis as measured by nitrogen content in different extracts after citrate fractionation of cheeses, in $\mathrm{pH} 4$.4-soluble nitrogen and $5 \%$ phosphotungstic acid-soluble nitrogen, respectively. The presence of copper appears to positively regulate the sensory characteristics of the cheese produced in our conditions; in particular, consistency was affected significantly. The role of the Lb. rhamnosus Lc705 protective strain has not been shown to have important effects on most of the parameters that influence the final quality of the cheeses. Although the traditional plating systems for revealing bacterial populations during cheese manufacture did not reveal any drastic differences caused by the presence of copper, the results from chemical and sensory analyses suggest that its use plays a significant role in the regulation of bacterial physiological and biochemical activities, which in turn affect the sensory quality of Emmental cheese.

Key words: copper, Emmental cheese, starter and adjunct culture, cheese quality

\section{INTRODUCTION}

Emmental cheese, also known as Swiss cheese, is a widespread cheese type that is produced in many industrialized countries; however, its manufacture may

Received May 16, 2011.

Accepted June 21, 2011.

${ }^{1}$ Corresponding author: tapani.alatossava@helsinki.fi vary depending on the place of origin. Production of Swiss Emmental uses copper vats, whereas in Finland, the manufacture of Emmental cheese is carried out in stainless steel cheese vats. Finnish Emmental includes the addition of $\mathrm{Cu}$ as a $\mathrm{Cu}$ sulfate solution at a level that will ensure concentrations of $\mathrm{Cu}$ in the final cheese close to that of traditional Swiss Emmental. In many other countries, stainless steel cheese vats are used but without the addition of copper.

The inhibitory effects of copper on the starters and adjunct cultures related to Emmental cheese production have been demonstrated in a species- and straindependent manner (Maurer et al., 1975; Mato Rodríguez and Alatossava, 2008) On the other hand, it is claimed that during the making of raw milk cheese, copper regulates an important part of the ripening process by influencing proteolytic enzymes as well as the activity of the microorganism present (Sieber et al., 2006). Copper levels that are too low result in cheese with poor flavor, in part because the ripening process is too rapid (Sieber et al., 2006). Although many cheese makers believe that $\mathrm{Cu}$ has a beneficial effect on the final quality of Emmental, few studies have been carried out to clarify the role of $\mathrm{Cu}$ in the final quality (Mueller et al., 1952; Kiermeier et al., 1961; Maurer et al., 1975). These studies suggest that under- or overdosing of copper may cause quality defects, predominantly through its effects on propionic bacterial fermentation.

The principal starters used in the production of Emmental cheese are thermophilic lactic acid bacteria (LAB) and a mixture of Streptococcus thermophilus spp. and Lactobacillus spp., including Lactobacillus helveticus or Lactobacillus. delbrueckii ssp. lactis. Facultative heterofermentative lactobacilli (FHL) are currently used as adjunct cultures to slow propionic acid fermentation. Propionibacteria, including the species Propionibacterium freudenreichii ssp. shermanii and $P$. freudenreichii ssp. freudenreichii, are used as secondary starters to achieve the characteristic eyes and nutty flavor (Fröhlich-Wyder and Bachmann, 2004).

In the manufacture of Emmental cheese, strong proteolysis, in addition to intense propionic acid fermenta- 
tion, may be the primary causes of late fermentation (Baer and Ryba, 1999). Lactobacillus helveticus strains are responsible for the liberation of a large quantity of small peptides in Emmental cheese, and simultaneously, the presence of small peptides and free amino acids stimulates the growth of propionic acid bacteria (Baer and Ryba, 1999). Because of its intensive peptidolytic activity, $L b$. helveticus has been replaced in traditional Swiss cheese by Lb. delbrueckii ssp. lactis. However, the strong proteolytic activity of Lb. helveticus is preferred by many manufacturers around the world to accelerate proteolysis and shorten the ripening period, thereby lowering the cost of production (Fröhlich-Wyder and Bachmann, 2004). The manufacture of Finnish Emmental also differs from the traditional Swiss process because it employs pasteurization $\left(72^{\circ} \mathrm{C} / 15 \mathrm{~s}\right)$ of the milk and uses $L b$. helveticus strains. A previous study (Mato Rodríguez and Alatossava, 2008) investigated the effect of $\mathrm{Cu}$ on starters and adjunct cultures used in the manufacture of Emmental cheese. That study revealed that among $3 \mathrm{Lb}$. helveticus strains tested, 2 were significantly more sensitive to $\mathrm{Cu}$ than those of the $L b$. delbrueckii species included in the study. The most sensitive species among the 3 species tested was Lactobacillus rhamnosus. The production of Emmental cheese in Finland also includes the addition of certain FHL strains, belonging to $L b$. rhamnosus species, as protective strains especially against clostridia such as Clostridium tyrobutyricum spoilage bacteria. Cheeses produced with FHL (Lb. casei and Lb. rhamnosus) show an inhibition of propionibacteria up to $80 \%$ compared with controls (Jimeno et al., 1995). The citrate metabolism of FHL seems to cause this inhibition, because citrate-negative mutants show a much lower inhibitory effect (Jimeno, 1997). Perez Chaia et al. (1987) postulated that the ratio of citrate to copper concentration plays an important role in the inhibition of propionibacteria.

In this study, we aimed to elucidate the roles of $\mathrm{Cu}$ in the manufacture of Finnish Emmental. Consequently, cheeses were produced with or without the copper supplement and with or without an FHL strain of $L b$. rhamnosus that is currently used as a protective culture in large-scale manufacture of Finnish Emmental.

\section{MATERIALS AND METHODS}

\section{Cheese Manufacture}

Small-scale experimental Emmental cheeses were produced in stainless steel vats from mildly pasteurized $\left(72^{\circ} \mathrm{C} / 15 \mathrm{~s}\right)$ milk $(100 \mathrm{~L})$, using the procedure of the dairy pilot plant of the Food and Environmental Sci- ence Department at the University of Helsinki (Figure 1 ). The general protocol used in the production was as follows: $0.2 \%$ (wt/vol) of Streptococcus thermophilus T101 and $0.1 \%$ (wt/vol) of Lb. helveticus K16 starters were added to $100 \mathrm{~L}$ of pasteurized milk following the addition of $30 \mathrm{~g}$ of $\mathrm{CaCl}_{2}$. Lactobacillus rhamnosus Lc705 was added as a protective strain at 0.01\% (wt/vol) followed by addition of a secondary culture of P. freundereichii ssp. freundereichii $\mathrm{P} 131$ at $0.01 \%$ (wt/vol). A solution of copper sulfate $(1 \% \mathrm{wt} / \mathrm{vol}$ $\left.\mathrm{CuSO}_{4} \cdot 5 \mathrm{H}_{2} \mathrm{O}\right)$ was added to obtain a final concentration of 1 to $1.5 \mathrm{mg} / \mathrm{L}$ in the cheesemilk. The milk was stirred for $22 \mathrm{~min}$ before the addition of $9.5 \mathrm{~g}$ of liquid rennet Chy-Max (600 international milk clotting units/ $\mathrm{mL}$ average activity) from Chr. Hansen (Hørsholm, Denmark). Following curd setting $\left(32^{\circ} \mathrm{C} / 35 \mathrm{~min}\right)$, cutting $\left(32^{\circ} \mathrm{C} / 13 \mathrm{~min}\right)$, and stirring $\left(32^{\circ} \mathrm{C} / 25 \mathrm{~min}\right), 30 \%$ of the whey was removed and replaced with $25 \%$ (vol/vol) water. The whey-curd mixture was scalded gradually to 51 to $53^{\circ} \mathrm{C}$ for 50 min before molding the curd at $49^{\circ} \mathrm{C}$. After the curd was pressed for $18 \mathrm{~h}$ and salted in brine (density $22^{\circ}$ Baumé) for $12 \mathrm{~h}$, the maturation schedule was as follows: $12^{\circ} \mathrm{C}$ for $10 \mathrm{~d}, 23^{\circ} \mathrm{C}$ for $25 \mathrm{~d}$, and $5^{\circ} \mathrm{C}$ until the end of ripening.

Raw milk used for cheese production was obtained from the dairy company Valio Ltd. (Helsinki, Finland). The concentrated starters used were also provided by Valio Ltd. Two sets of cheeses were produced on 2 consecutive days during 2 wk. The same batch of raw milk was used for 1 wk of cheese production. During the first week, one set of cheeses was made with the addition of copper in the cheesemilk as an aqueous solution of copper sulfate stock solution (1\%, wt/vol), and the other set was produced without the addition of copper. In the second week, the same procedure was applied, but the protective strain $L b$. rhamnosus Lc705 was not included in the manufacture. The cheeses were designated as follows: $\mathbf{C h C u}+\mathbf{L c 7 0 5}+=$ cheese produced with the addition of copper and the protective strain Lc705 into the cheesemilk; $\mathbf{C h C u - L c 7 0 5 + =}$ cheese produced without the addition of copper but with the addition of the protective strain Lc705 into the cheesemilk; $\mathbf{C h C u}+\mathbf{L c 7 0 5}-=$ cheese produced with the addition of copper but without the addition of the protective strain Lc705 into the cheesemilk; and $\mathbf{C h C u}-\mathbf{L c 7 0 5}-=$ cheese produced without addition of copper or the protective strain Lc705 into the cheesemilk. From the 2 test cheeses (about $5 \mathrm{~kg}$ each) produced from each cheese vat (100 L milk), one test cheese was used for sampling for the different analyses and the other one was kept intact for sensory evaluation after $90 \mathrm{~d}$ of ripening. Representative samples from each test cheese were taken after pressing (d 1), during 


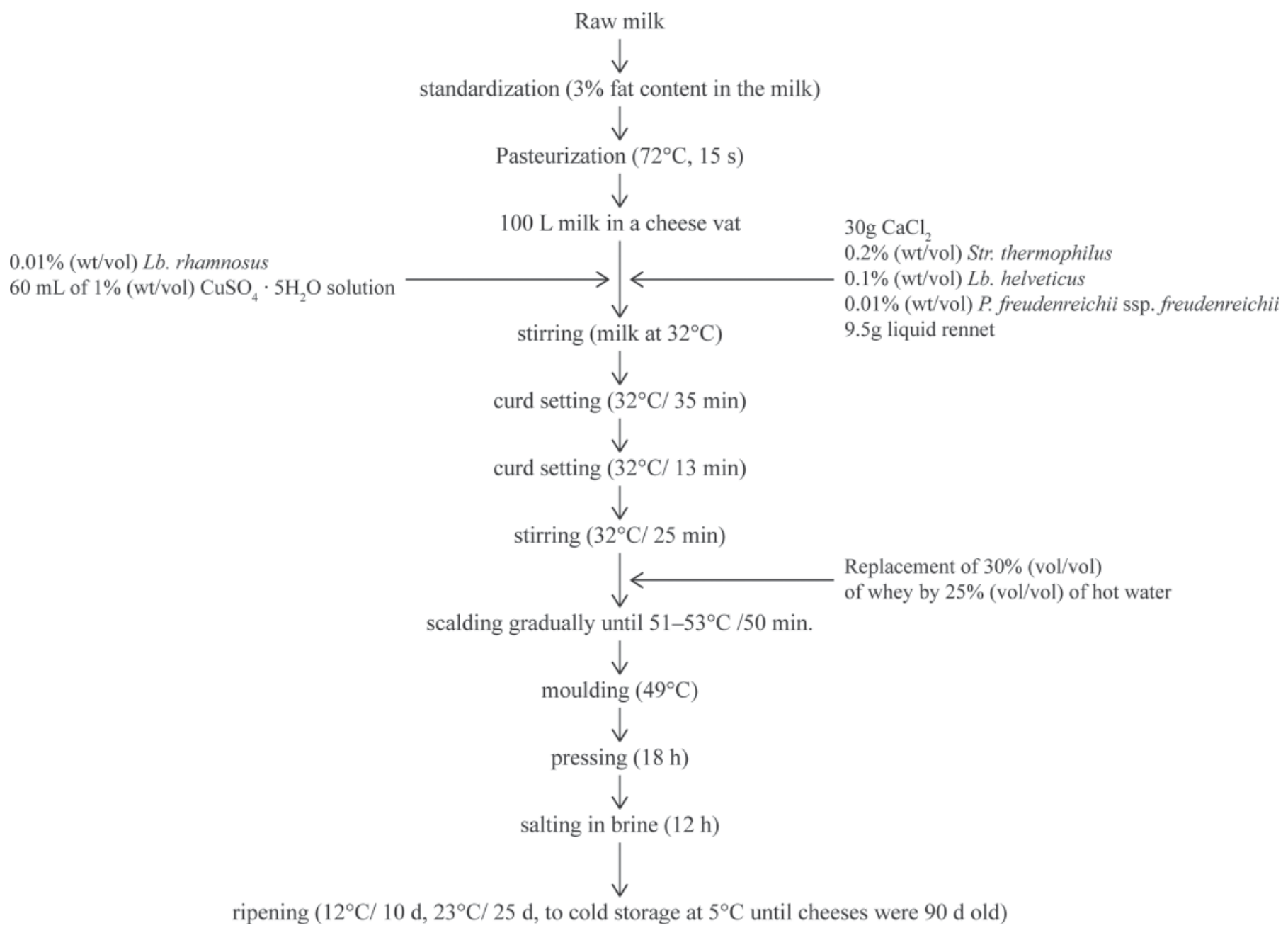

Figure 1. Flow diagram for the manufacture of Emmental test cheese.

cold room storage for ring formation (d 7), close to the end of warm room fermentation (d 30), and during cold room ripening (d 60 and 90).

\section{Microbiological Analysis of Milk and Cheeses}

Microorganisms were enumerated in raw milk, pasteurized milk, milk before rennet addition, and cheeses at $1,7,30,60$, and $90 \mathrm{~d}$ (of ripening). To measure starter viability in cheeses, $10 \mathrm{~g}$ of the cheese sample was homogenized using a stomacher (Colworth stomacher 400, Seward Ltd., London, UK) for 3 min in 90 $\mathrm{g}$ of trisodium citrate solution $(20 \mathrm{~g} / \mathrm{L})$. Subsequent dilutions were prepared using a $0.85 \%$ (wt/vol) saline solution. Corresponding serial dilutions were inoculated on different media that are currently used for revealing different species in cheeses. All microbiological sampling and measurements in milk and cheeses were performed in duplicate and the mean values results are reported.
The total bacterial counts of raw and pasteurized milk were enumerated on plate count agar (Lab M Ltd., Lancashire, UK), and the plates were incubated at $30^{\circ} \mathrm{C}$ for $48 \mathrm{~h}$. Coliforms were enumerated in pasteurized milk and in fresh cheeses using violet red bile lactoseagar (Lab M Ltd.), and the plates were incubated at $30^{\circ} \mathrm{C}$ for $24 \mathrm{~h}$. Yeast and molds were enumerated in pasteurized milk and in cheese at different sampling points using yeast glucose chloramphenicol agar (Merck, Darmstadt, Germany), and the plates were incubated at $25^{\circ} \mathrm{C}$ for 5 d. Streptococcus thermophilus was enumerated using M17 lactose (M17-L) agar (Lab M Ltd.) after the addition of starter to the milk and cheeses at the different sampling points during ripening. The lactose concentration in the medium was adjusted to $2 \%$ (wt/vol) after autoclaving. Plates were incubated anaerobically at $42^{\circ} \mathrm{C}$ for $48 \mathrm{~h}$. The total number of lactobacilli was enumerated using de Man, Rogosa, and Sharpe (MRS) agar (Lab M Ltd.) after the addition of starter to the 
milk and cheeses at the different sampling points during ripening. The plates were incubated anaerobically at $37^{\circ} \mathrm{C}$ for $48 \mathrm{~h}$. Nonstarter lactobacilli were enumerated using MRS agar supplemented with vancomycin (50 mg/L of agar) after the addition of starter to the milk and cheeses at the different sampling points during ripening time. Plates were incubated anaerobically at $37^{\circ} \mathrm{C}$ for $48 \mathrm{~h}$. Vancomycin is used in MRS agar to inhibit the growth of certain species of lactobacilli such as Lb. helveticus. However, the growth of other Lactobacillus species such as Lb. rhamnosus is possible in the presence of vancomycin. We used MRS agar supplemented with vancomycin at $50 \mathrm{mg} / \mathrm{L}$ to count the levels of the protective strain $L b$. rhamnosus Lc705 in test cheeses and to elucidate the effects of the presence of $\mathrm{Cu}$ on growth and survival of Lb. rhamnosus Lc705. We also used MRS-vancomycin agar by comparing the counts on MRS and MRS-vancomycin for the other set of cheeses in which the protective strain was not added to evaluate the evolution of $L b$. helveticus during ripening. The levels of $L b$. helveticus are masked when both starter and protective strains of Lactobacillus are present at high levels in cheesemilk, especially at the beginning of the process. Lactobacillus helveticus strains are autolytic, and they are not usually revealed after a certain period of ripening. However, Lactobacillus species that belong to nonstarter LAB, usually $L b$. casei, $L b$. rhamnosus, and Lb. plantarum, remained at high levels during the process (Kocaoglu-Vurma et al., 2008). Propionibacteria were enumerated using Na-lactate agar (Tuomola et al., 1999) after addition of the starter to the milk and cheeses at different sampling points during ripening. The medium consisted $5 \mathrm{~g}$ of tryptone, 10 $\mathrm{g}$ of yeast extract, $10 \mathrm{~g}$ of $\beta$-glycerophosphate, $16.8 \mathrm{~mL}$ of $50 \%$ (wt/wt) Na-lactate solution, $16 \mathrm{~g}$ of agar, and $1,000 \mathrm{~mL}$ of distilled water; the $\mathrm{pH}$ after autoclaving was $7.2 \pm 0.2$. The plates were incubated anaerobically at $30^{\circ} \mathrm{C}$ for $5 \mathrm{~d}$.

\section{Chemical Analysis of Milk and Cheeses}

The total composition of raw and standardized milk was measured using a MilkoScan Minor type 78100 (Foss Analytical A/S, Hillerød, Denmark). pH measurements were performed in cheeses at all sampling points using a waterproof multi parameter PCS tester 35 (Oakton Instruments, Vernon Hills, IL). The Cu content, degree of proteolysis, and concentration of organic acids were measured in 7-, 30-, 60-, and 90-d-old cheeses. The cheese samples collected at each sampling point for $\mathrm{Cu}$ content and proteolysis analysis were grated, divided into portions, stored in crimp-neck vial glasses $(50-\mathrm{mL}$ capacity) and frozen at $-20^{\circ} \mathrm{C}$. The copper content was determined at MTT Agrifood Research Finland (Jokio- inen, Finland) by inductively coupled plasma emission spectrometry with Thermo Jarrell Ash Iris Advantage (Thermo Jarrell Ash, Franklin, MA) at emission spectra of $327.3 \mathrm{~nm}$, following the procedure of Kumpulainen and Paakki (1987). Proteolysis was performed using the fractionation of a citrate dispersion of cheese (IDF, 1999), and the nitrogen content in the different soluble fractions obtained from the fractionation protocol was determined by the method of Kjeldahl (AOAC, 2000; method 33.2.11, 991.20). For organic acids determination, grated cheese was stored in 20-mL crimp-neck amber vials, injected with nitrogen, and frozen at $-20^{\circ} \mathrm{C}$ until the analysis was performed. Organic acid analysis was performed by HPLC using the general protocol reported by Mullin and Emmons (1997) and Akalin et al. (2002) with some modifications: a cheese sample $(2 \mathrm{~g})$ was homogenized in a centrifuge tube for $1 \mathrm{~min}$ with $10 \mathrm{~mL}$ of $0.005 \mathrm{~N} \mathrm{H}_{2} \mathrm{SO}_{4}$ using a Ystral homogenizer (Ystral, Dottingen, Germany). The homogenized sample was then extracted in a magnetic stirrer for $1 \mathrm{~h}$. After extraction, the sample was centrifuged at $6,000 \times g$ for $5 \mathrm{~min}$ and filtered into an autosampler vial through 0.45 - and $0.2-\mu \mathrm{m}$ membrane filters. The organic acids were analyzed at MTT Agrifood Research Finland by using an Agilent 1100-series HPLC (Agilent Technologies, Santa Clara, CA) equipped with a diode array detector. The analytical column was a Rezex RFQ Fast Acid $(100 \times 7.8 \mathrm{~mm}$, Phenomenex, Torrance, $\mathrm{CA}$ ), and the mobile phase was run under 0.005 $N \mathrm{H}_{2} \mathrm{SO}_{4}$ at $0.5 \mathrm{~mL} / \mathrm{min}$. Organic acids were quantified at $210 \mathrm{~nm}$. Compositional analyses were carried out in 90-d-old cheeses, and they included the determination of total solids content (IDF, 1982) fat content by the Gerber van Gulik method (ISO, 1975), total nitrogen content by the Kjeldahl method (AOAC, 2000), and salt content, which was determined using a chloride analyzer (model 926S, Sherwood Scientific Ltd., Cambridge, UK) following the procedure of Johnson and Olson (1985).

\section{Sensory Analysis of Cheeses}

The sensory analysis was performed using a quality scoring by the FIL-IDF 99C method (IDF, 1997), a grading method using a 5-point quality scale for the appearance of the attributes, consistency, and flavor. The cheeses were assessed by an expert panel $(\mathrm{n}=5)$ of the Finnish Food Safety Authority Evira in Helsinki. The panel consists of experts who have been performing quality grading of different cheeses for several years $(>3$ $\mathrm{yr})$. The descriptions of the scores in the scale are as follows (whole numbers are used): $5=$ conformity with the pre-established sensory specification, $4=$ minimal deviation from the pre-established sensory specifica- 
Table 1. General composition and microbiology of raw and pasteurized milk used for the manufacture of Emmental test cheeses

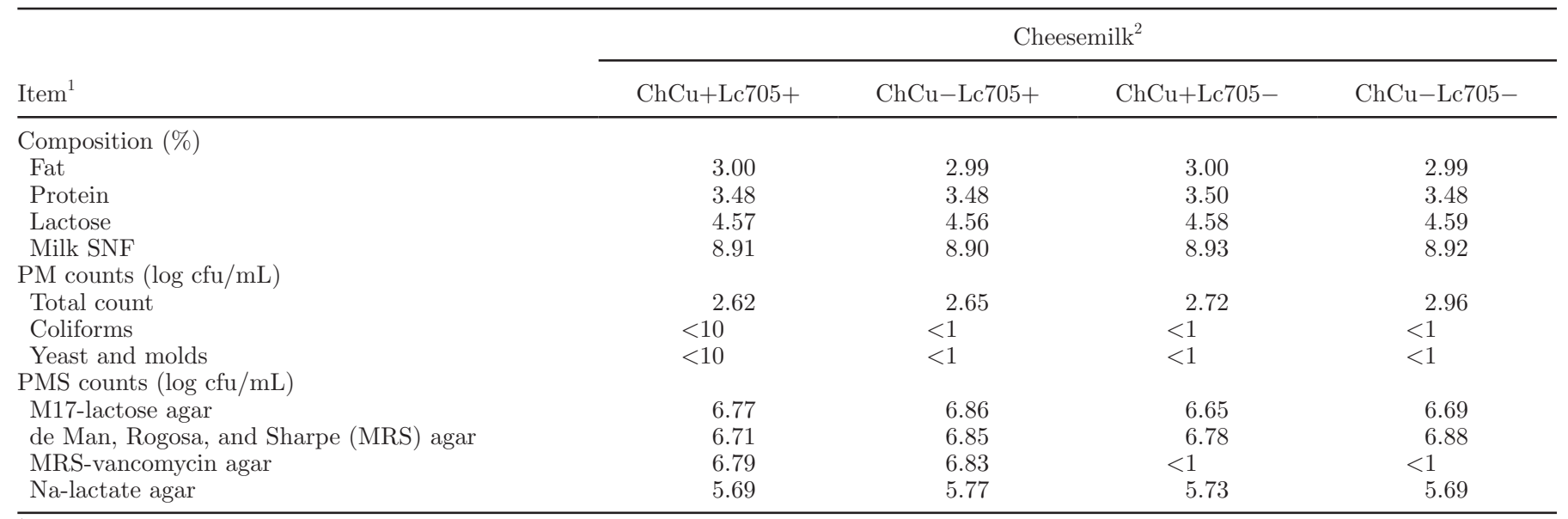

${ }^{1} \mathrm{PM}=$ pasteurized milk; PMS = pasteurized milk after starter addition.

${ }^{2} \mathrm{ChCu}+\mathrm{Lc} 705+=$ cheese produced with the addition of copper and the protective strain Lactobacillus rhamnosus Lc705 (Lc705); $\mathrm{ChCu}-$ Lc705+ = cheese produced without the addition of copper but with the addition of the protective strain Lc705; ChCu+Lc705- $=$ cheese produced with the addition of copper but without the addition of the protective strain $\mathrm{Lc705}$; and $\mathrm{ChCu}-\mathrm{Lc} 705-=$ cheese produced without the addition of copper or the protective strain Lc705.

tion, 3 = noticeable deviation from the pre-established sensory specification, $2=$ considerable deviation from the pre-established sensory specification, $1=$ very considerable deviation from the pre-established sensory specification, and $0=$ unfit for human consumption. If a panelist gives a score of 3 or less, a deviation from the specification (defect) must be described. The nomenclature of terms is defined in the method. The samples were evaluated at $14 \pm 2{ }^{\circ} \mathrm{C}$ and coded with a 3 -digit random number.

\section{Statistical Analysis}

The results of the proteolysis analysis were analyzed by 2-way ANOVA (factors: copper and Lc705, and covariant: age), and the results of the quality scoring were analyzed by 1-way ANOVA. Statistically significant differences $(P<0.05)$ in quality scoring were tested by Tukey's honestly significant difference test. Principal component analysis (PCA) was used to visualize the differences between cheeses in the quality scoring. Statistical tests were gained by PASW Statistics (18.0.0, 2009, SPSS Inc., Chicago, IL), Statistics for Windows (7.0, 2000, Analytical Software, Tallahassee, FL), and Unscrambler (9.2, 2005, CAMO ASA, Oslo, Norway).

\section{RESULTS}

\section{Composition, Microbiological Quality, and Level of Starters in Cheesemilk}

The raw milk used for making cheese had the following composition: fat: $4.57 \pm 0.10 \%$ (wt/wt), protein:
$3.40 \pm 0.01 \%$ (wt/wt), lactose: $4.45 \pm 0.09 \%$ (wt/wt), and milk solids nonfat: $8.79 \pm 0.05 \%$ (wt/wt). The total bacterial count in raw milk for the first set of cheeses produced was $4.23 \log \mathrm{cfu} / \mathrm{mL}$, on average, and that for the second set of cheeses was $3.90 \log \mathrm{cfu} / \mathrm{mL}$. The average values of the gross composition, microbiological quality, and starter levels in pasteurized milk used for making cheese are shown in Table 1.

\section{Effect of Copper on the Starters and Adjunct Cultures}

As shown in Figure 2a, the counts on M17-L agar did not show important differences with the presence of $\mathrm{Cu}$ in young cheeses, although some differences could be observed in cheeses made without the protective strain Lc705, in which counts were lower compared with the cheeses produced with this strain. Nevertheless, the counts on M17-L agar remained much higher in cheeses from 60 to $90 \mathrm{~d}$ of ripening when produced without the protective strain Lc705 compared with cheeses of corresponding age produced with the protective strain (Figure 2a).

As can be seen in Figure 2b, the counts on MRS were similar for all cheeses at different sampling points, with the exception of the 60- and 90-d samples, in which the counts were much lower in cheeses produced without Lb. rhamnosus Lc705.

Cheeses produced with or without $\mathrm{Cu}$ did not differ substantially, as revealed by the counts on MRSvancomycin agar (Figure 2c). In cheeses without the protective strain, the values were negative at $\mathrm{d} 1$ for cheeses made with $\mathrm{Cu}$, but a few colonies were observed 

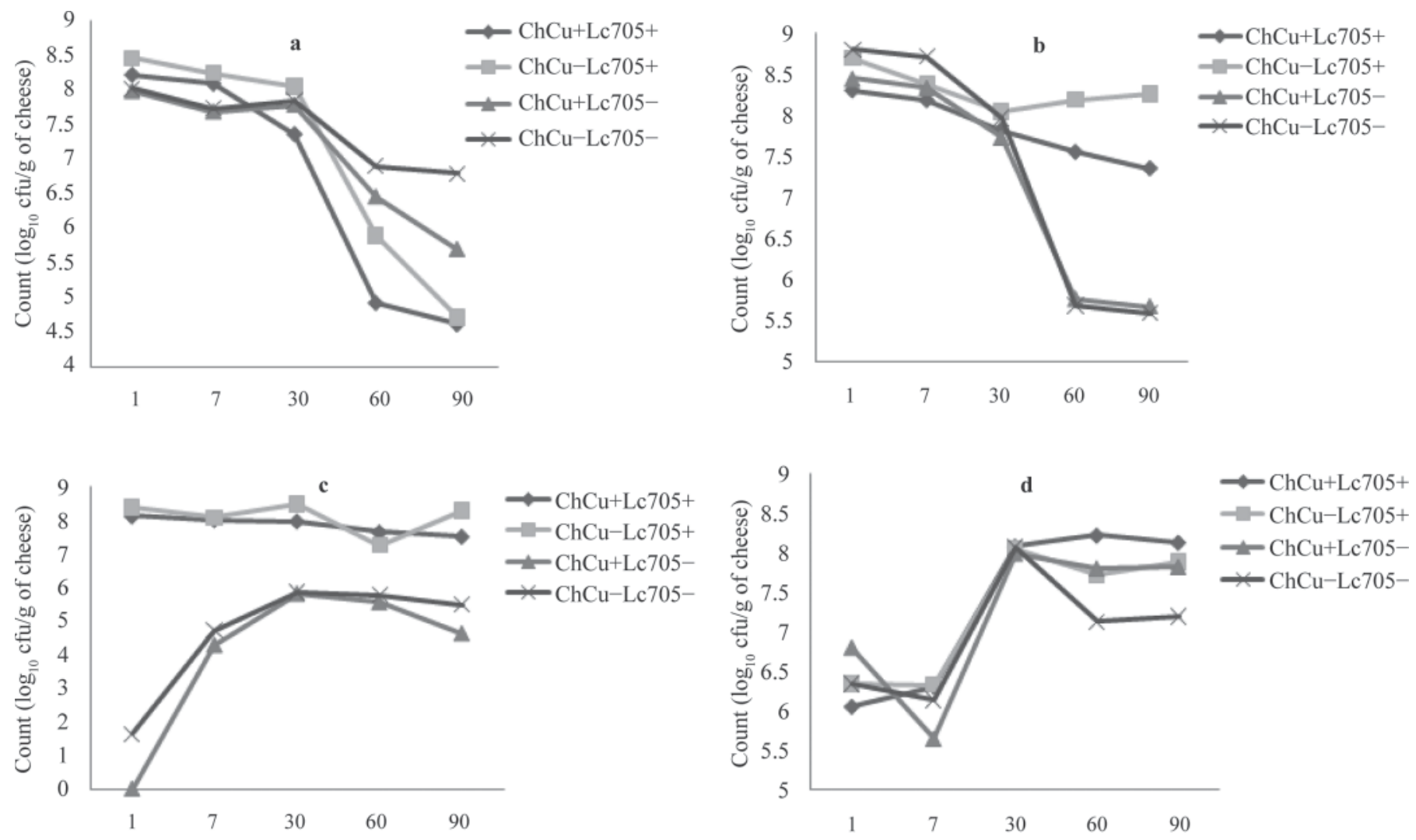

Ripening time (d)

Ripening time (d)

Figure 2. Counting results in (a) M17-lactose (M17-L) agar, (b) de Man, Rogosa, and Sharpe (MRS) agar, (c) MRS-vancomycin agar, and (d) Na-lactate agar at different ripening periods. $\mathrm{ChCu}+\mathrm{Lc} 705+=$ cheese produced with the addition of copper and the protective strain Lactobacillus rhamnosus Lc705 (Lc705); $\mathrm{ChCu}-\mathrm{Lc} 705+=$ cheese produced without the addition of copper but with the addition of the protective strain Lc705; $\mathrm{ChCu}+\mathrm{Lc705}-=$ cheese produced with the addition of copper but without the addition of the protective strain Lc705; and $\mathrm{ChCu}-\mathrm{Lc} 705-=$ cheese produced without the addition of copper or the protective strain Lc705.

at this sampling point in cheeses made without $\mathrm{Cu}$. After $7 \mathrm{~d}$, the counts gradually increased in these 2 sets of cheeses, which could be attributed either to some nonstarter LAB that can be found in this type of cheese during ripening or to the possibility that contamination with the same strain of $L b$. rhamnosus Lc705 occurred at some point. However, no differences in the counts were seen when comparing $\mathrm{ChCu}+\mathrm{Lc} 705-$ and $\mathrm{ChCu}-$ Lc705- cheeses from 30 to $90 \mathrm{~d}$ of ripening (Figure 2c).

The milk used in our manufacturing process was submitted to a mild pasteurization, similar to that used in Emmental production on an industrial scale in Finland, and propionic bacteria were inoculated into the cheese vat at the level of 5 to 6 log-units. Propionic acid fermentation begins after the cheeses have been placed in the warm room, and the counts of this population increase to levels between 8 and 9 log-units and usually remain at high levels until the end of the ripening process. The counts on Na-lactate agar did not reveal any effect of the presence of $\mathrm{Cu}$ on the propionic bacteria population; the counts were very similar throughout the ripening process (Figure 2d). Lactobacillus rhamnosus Lc705 is also used to slow propionic fermentation by controlling growth of propionibacteria, but no differences were found in counts between cheeses produced with or without this strain. A slight decrease in the propionic bacterial population in $\mathrm{ChCu}-\mathrm{Lc} 705$ - was observed only after $60 \mathrm{~d}$ of ripening, which accounts for 1 log-unit difference compared with $\mathrm{ChCu}+\mathrm{Lc} 705+$ (Figure 2d).

\section{Evolution of Chemical Composition During Ripening}

During the cheesemilk coagulation period and curd treatment in the cheese vat, the $\mathrm{pH}$ remained constant and close to that of the initial $\mathrm{pH}$ in cheesemilk because the process was performed in such a way that no acidification was allowed during this period. A decrease in $\mathrm{pH}$ is usually observed during pressing time. In our process, the $\mathrm{pH}$ was determined in the cheeses after $2 \mathrm{~h}$ 
of pressing. At this point, $\mathrm{pH}$ values were slightly lower in cheeses produced without $\mathrm{Cu}$ and higher in cheeses produced without Lb. rhamnosus Lc705 compared with the cheeses produced with Lc705 (pH 5.70 for $\mathrm{ChCu}+\mathrm{Lc} 705+, \mathrm{pH} 5.65$ for $\mathrm{ChCu}-\mathrm{Lc} 705+, \mathrm{pH} 6.00$ for $\mathrm{ChCu}+\mathrm{Lc} 705-$, and $\mathrm{pH} 5.94$ for $\mathrm{ChCu}-\mathrm{Lc} 705-)$. At the end of the pressing period, the $\mathrm{pH}$ differences were a little more pronounced between cheeses made with or without $\mathrm{Cu}$, especially in those cheeses made with the Lb. rhamnosus Lc705 supplement (pH 5.46 and 5.29, respectively).

The average $\mathrm{pH}$ values, copper content, and composition at the final ripening point $(90 \mathrm{~d})$ for all cheeses are shown in Table 2. During cheese ripening, the $\mathrm{pH}$ values in cheeses containing added copper remained higher after $7 \mathrm{~d}$ in cold storage (the period for cheese rind formation), especially in cheeses produced with the Lb. rhamnosus Lc705 strain added. Later, during ripening, these $\mathrm{pH}$ differences disappeared. The $\mathrm{pH}$ values of cheeses produced without the Lb. rhamnosus Lc705 protective strain were higher at all timepoints compared with the set of cheeses produced with this strain. However, the differences in $\mathrm{pH}$ values were not very pronounced between $\mathrm{ChCu}+\mathrm{Lc} 705-$ and $\mathrm{ChCu}-$ Lc705- cheeses.

As shown in Table 2, the $\mathrm{Cu}$ content was slightly higher in the set of cheeses produced with the $L b$. rhamnosus Lc705 strain. The set of cheeses made with or without Lc705 were produced using different sources of raw milk. The higher background $\mathrm{Cu}$ content in the cheesemilk may explain the higher content in the first set of cheeses; the corresponding values in the first and second sets of cheesemilk were 0.11 and 0.07 , respectively.

Emmental cheese is characterized by the resulting organic acids, which are produced from propionic acid bacterial fermentation. This fermentation plays a critical role in the ripening quality of this type of cheese by producing propionate, acetate, and $\mathrm{CO}_{2}$. The acids are important flavor components, and the eyes in the cheese are formed due to $\mathrm{CO}_{2}$ production (Piveteau, 1999).

To determine the effect of $\mathrm{Cu}$ on propionic bacterial activity, the content of the main organic acids that are metabolized during growth were monitored at different ripening points (Figure 3). The content of lactic acid at the 7 -d sampling point was not very different when comparing the same set of cheeses produced with or without $\mathrm{Cu}$ (Figure 3a). At this point, the cheeses produced with the protective strain $L b$. rhamnosus Lc705 had higher values of lactic acid compared with the cheeses without Lc705. By the end of the propionic acid fermentation period (30-d-old cheeses), the lactic acid content was considerably higher in cheeses containing added $\mathrm{Cu}$, independently of the initial values measured $(7 \mathrm{~d})$. These values remained higher until the end of maturation (90 d) compared with the $\mathrm{Cu}$ negative cheeses, with the exception of the 90-d-old $\mathrm{ChCu}-\mathrm{Lc} 705-$, which showed a slight increase in lactic acid content for unknown reasons (Figure 3a). Lower consumption of lactic acid by propionic acid bacteria suggests some inhibition in their activity.

Pyruvic acid content was very similar at the 7 -d ripening point in all cheeses, but an increase was ob-

Table 2. Values of $\mathrm{pH}$ and copper content at different ripening times (d 1 to 90) and composition ( \pm SD) of 90-d-old Emmental cheeses

\begin{tabular}{|c|c|c|c|c|}
\hline \multirow[b]{2}{*}{ Item } & \multicolumn{4}{|c|}{ Cheese sample $^{1}$} \\
\hline & $\mathrm{ChCu}+\mathrm{Lc} 705+$ & $\mathrm{ChCu}-\mathrm{Lc} 705+$ & $\mathrm{ChCu}+\mathrm{Lc} 705-$ & $\mathrm{ChCu}-\mathrm{Lc} 705-$ \\
\hline d 1 & 5.46 & 5.29 & 5.56 & 5.51 \\
\hline d 7 & 5.67 & 5.47 & 5.71 & 5.60 \\
\hline d 30 & 5.53 & 5.59 & 5.63 & 5.61 \\
\hline d 60 & 5.70 & 5.68 & 5.79 & 5.72 \\
\hline d 7 & 15.0 & 1.56 & 14.1 & 1.10 \\
\hline d 30 & 15.2 & 1.69 & 15.0 & 1.14 \\
\hline d 60 & 14.8 & 1.63 & 14.4 & 1.14 \\
\hline d 90 & 15.4 & 1.60 & 14.2 & 1.13 \\
\hline \multicolumn{5}{|c|}{ Composition (\%) of 90 -d-old cheeses } \\
\hline Fat & $31.25 \pm 0.35$ & $29.50 \pm 0.00$ & $31.00 \pm 0.00$ & $30.25 \pm 0.35$ \\
\hline Protein & $28.69 \pm 0.66$ & $30.14 \pm 0.52$ & $28.69 \pm 0.30$ & $29.30 \pm 0.18$ \\
\hline
\end{tabular}

${ }^{1} \mathrm{ChCu}+\mathrm{Lc} 705+=$ cheese produced with the addition of copper and the protective strain Lactobacillus rhamnosus Lc705 (Lc705); ChCu$\mathrm{Lc} 705+=$ cheese produced without the addition of copper but with the addition of the protective strain $\mathrm{Lc} 705 ; \mathrm{ChCu}+\mathrm{Lc} 705-=$ cheese produced with the addition of copper but without the addition of the protective strain Lc705; and $\mathrm{ChCu}-\mathrm{Lc} 705-=$ cheese produced without the addition of copper or the protective strain Lc705. 

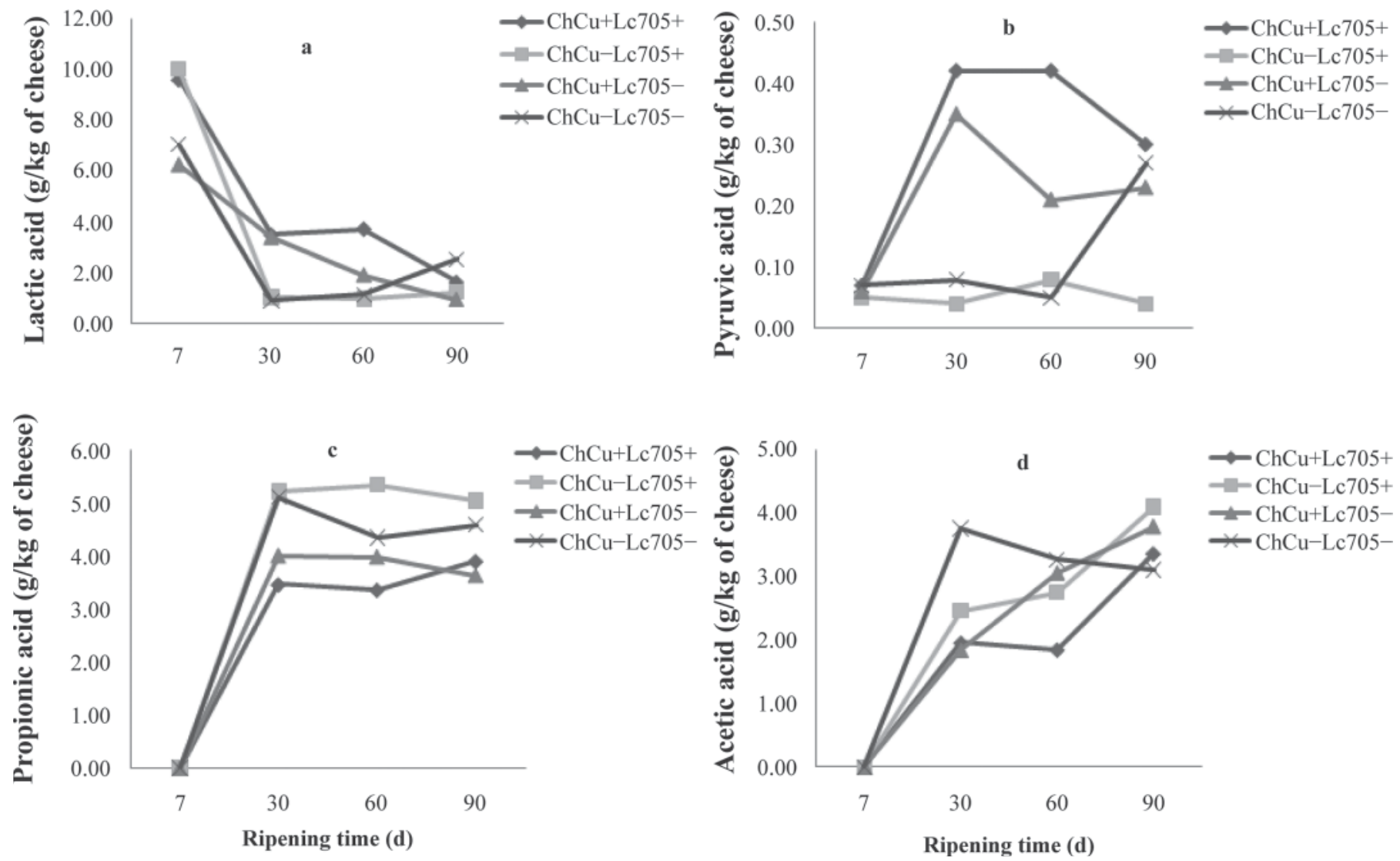

Figure 3. Development of organic acids in test cheeses at different ripening points: (a) lactate, (b) pyruvate, (c) propionate, and (d) acetate. $\mathrm{ChCu}+\mathrm{Lc} 705+=$ cheese produced with the addition of copper and the protective strain Lactobacillus rhamnosus Lc705 (Lc705); ChCu-Lc705+ $=$ cheese produced without the addition of copper but with the addition of the protective strain Lc705; ChCu+Lc705- = cheese produced with the addition of copper but without the addition of the protective strain Lc705; and $\mathrm{ChCu}-\mathrm{Lc} 705-=$ cheese produced without the addition of copper or the protective strain Lc705.

served at the end of warm-room fermentation in cheeses containing supplemented $\mathrm{Cu}$ (Figure 3b). The accumulation of this acid in cheeses at $30 \mathrm{~d}$ was followed by a gradual decrease until the end of maturation. A significant relative increase of this acid was detected in $\mathrm{ChCu}-\mathrm{Lc} 705-$ at $90 \mathrm{~d}$.

The formation of propionate in the cheese during warm-room fermentation is shown in Figure 3c. Cheeses with supplemented $\mathrm{Cu}$ had lower contents of propionic acid at this sampling point, and in cheeses without $\mathrm{Cu}$, the amount of propionic acid remained higher until the end of ripening. The absence of the protective strain Lc705 in the second set of cheeses did not have any noticeable effect on the level of propionic acid formation. Similarly, the levels of acetic acid after $30 \mathrm{~d}$ of fermentation were higher in cheeses where $\mathrm{Cu}$ was not added to the cheesemilk, but in this case the difference was more pronounced when $L b$. rhamnosus Lc705 was also absent (Figure 3d). However, the higher content of acetic acid observed at this point for $\mathrm{ChCu}-\mathrm{Lc} 705-$ disappeared later during maturation when increases in acetic acid content were observed in the rest of the cheeses. At the end of ripening (90 d), the acetic acid contents were similar in all cheeses (Figure 3d). The ratio between propionate and acetate was similar in all cheeses at $90 \mathrm{~d}$ of ripening, at around 1:0.8, with the exception of $\mathrm{ChCu}+\mathrm{Lc} 705-$, in which the ratio was 1:1.

The results obtained from the statistical analysis of the data are shown in Figure 4, which was generated from the proteolysis analysis of cheeses when using the citrate fractionation method at 4 ripening times. The levels of pH 4.4-soluble nitrogen (4.4-SN) in Figure 4a, TCA-soluble nitrogen (TCA-SN) in Figure 4b, and phosphotungstic acid-soluble nitrogen (PTA-SN) in Figure $4 \mathrm{c}$ are expressed as proportions of total nitrogen (TN) in cheeses. The mean and standard deviation of TN of all cheeses was $45.49 \pm 0.94 \mathrm{~g} / \mathrm{kg}$. This is in the same range as reported for Finnish Emmental cheese (Pillonel et al., 2005). As expected, the age of the cheese mostly influenced the $\mathrm{N}$ levels of all fractions.

Copper had a significant effect on the level of 4.4-SN $(P<0.05)$. Supplemented $\mathrm{Cu}$ increased the level of 4.4- 

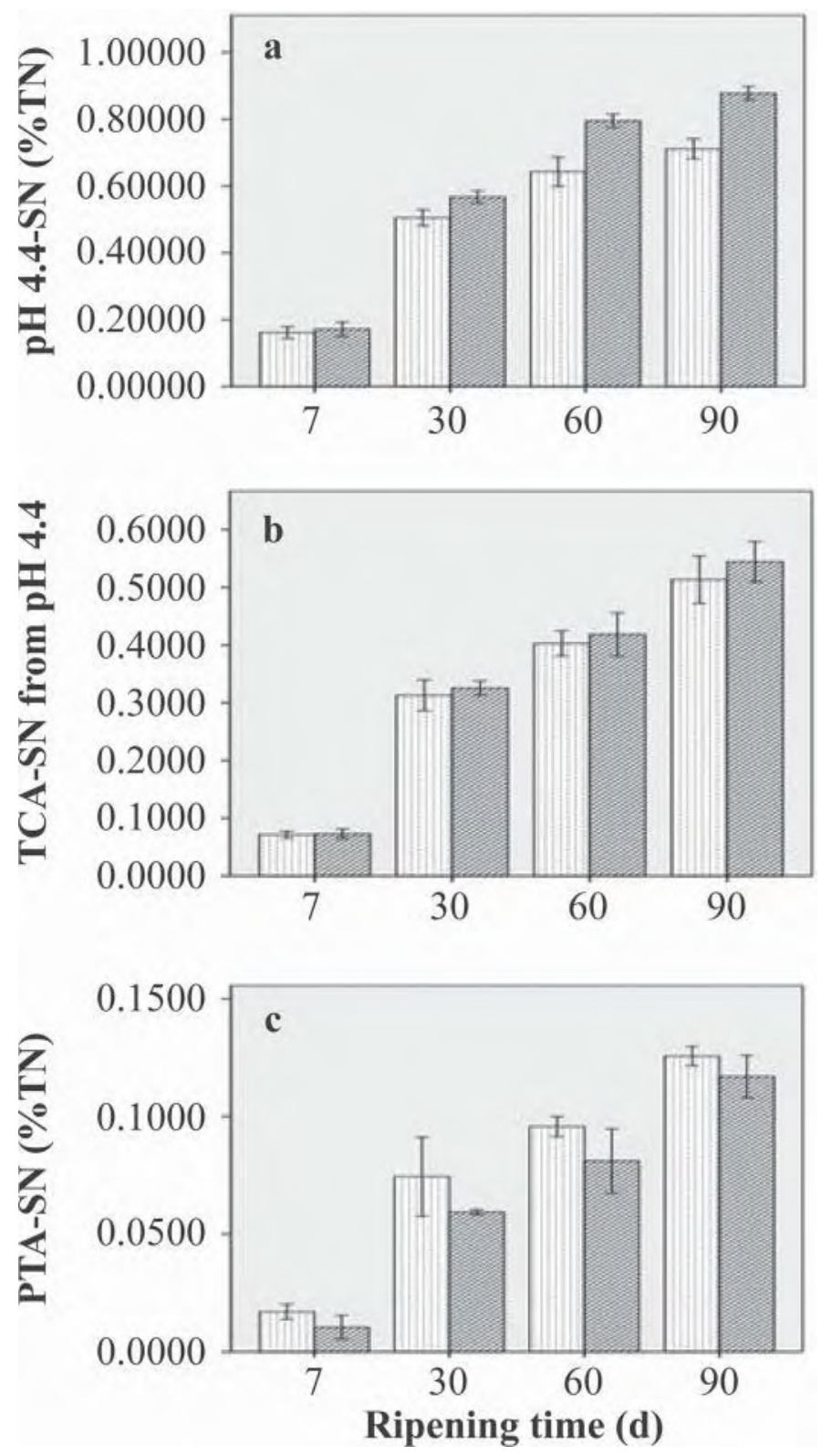

Figure 4. Mean and standard deviations of different nitrogen fractions in cheeses with (gray bar) or without (white striped bar) added copper: (a) $\mathrm{pH}$ 4.4-soluble nitrogen, (b) TCA-soluble nitrogen from $\mathrm{pH} 4.4$ soluble nitrogen, and (c) phosphotungstic acid-soluble nitrogen. $\mathrm{TN}=$ total nitrogen .

SN at every stage of ripening (Figure 4a). In addition, the level of TCA-SN increased in $\mathrm{Cu}$-supplemented cheeses at d 30 to 90, although the increase was not statistically significant (Figure 4b). On the contrary, the addition of $\mathrm{Cu}$ significantly decreased $(P<0.05)$ the level of PTA-SN in cheeses during ripening.

The use of the Lc705 protective strain did not have an effect on proteolysis at any stage (data not shown). In addition, the interaction of $\mathrm{Cu}$ and Lc705 was statistically insignificant in every fraction and at every stage.

\section{Sensory Analysis of Cheeses}

The results derived from the sensory evaluation of the cheeses are shown in Figure 5. The PCA revealed that all the cheeses differed from each other (Figure $5 a)$. Principal component 1 (PC1) explained $68 \%$ of the variance, and samples were mainly distributed along PC1 according to the supplement of $\mathrm{Cu}$. Moreover, consistency was observed with $\mathrm{Cu}$-positive samples, indicating that added $\mathrm{Cu}$ predominantly influenced the consistency positively. This was also seen in the ANOVA results, because the presence of added $\mathrm{Cu}$ had a statistically significant effect on the consistency of the cheeses (Figure 5b). Principal component 2 explained $28 \%$ of the variance, and samples were distributed along it according to the addition of the Lb. rhamnosus Lc705 protective strain. The effect of the protective strain on the appearance of the cheese was statistically significant in cheeses produced without $\mathrm{Cu}$ (Figure 5b); the differences in appearance were mostly attributed to eye formation in the cheeses. The addition of either $\mathrm{Cu}$ or the protective strain did not have statistically significant effects on the flavor of the cheeses. All the cheeses were given a low score on appearance, mainly because of problems with rind formation. However, the situation was similar for all cheeses and did not influence the evaluation of consistency and flavor.

\section{DISCUSSION}

According to the results of this study, the addition of copper during cheese-making influences the final characteristics of Emmental cheese to a certain extent. This holds true for the levels of the main organic acids (Figure 3), the degree of proteolysis (Figure 4), and the consistency of the cheeses (Figure 5). The presence of Lc705 protective strain appeared to influence primarily the appearance of the cheeses, particularly in those cheeses produced without $\mathrm{Cu}$.

The results obtained from the microbiological analysis of cheeses at the different sampling points did not reveal many differences in the cheeses produced with or without $\mathrm{Cu}$ in any of the counting systems used. These results could be attributed in part to the lack of specificity of the plating systems and to the incubation conditions used to account for the specific populations of starters and adjunct cultures. The M17-L agar is currently used for enumerating Lactococcus and Streptococcus species in cheeses and other dairy fermented products, but it is not totally selective, similar to most of the media used for revealing certain types of bacteria in food matrices (Tharmaraj and Shah, 2003). A decline in bacterial counts after $60 \mathrm{~d}$ of ripening to around $5 \log \mathrm{cfu} / \mathrm{mL}$ is regularly seen for Strep. thermophilus 
a

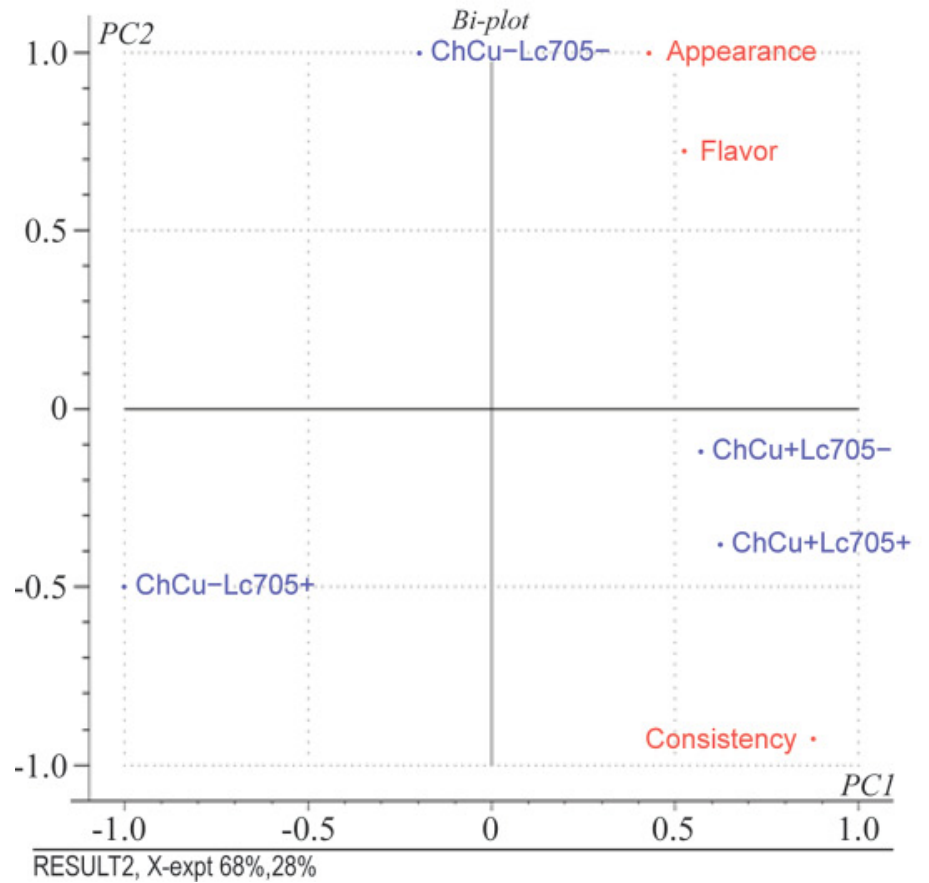

b

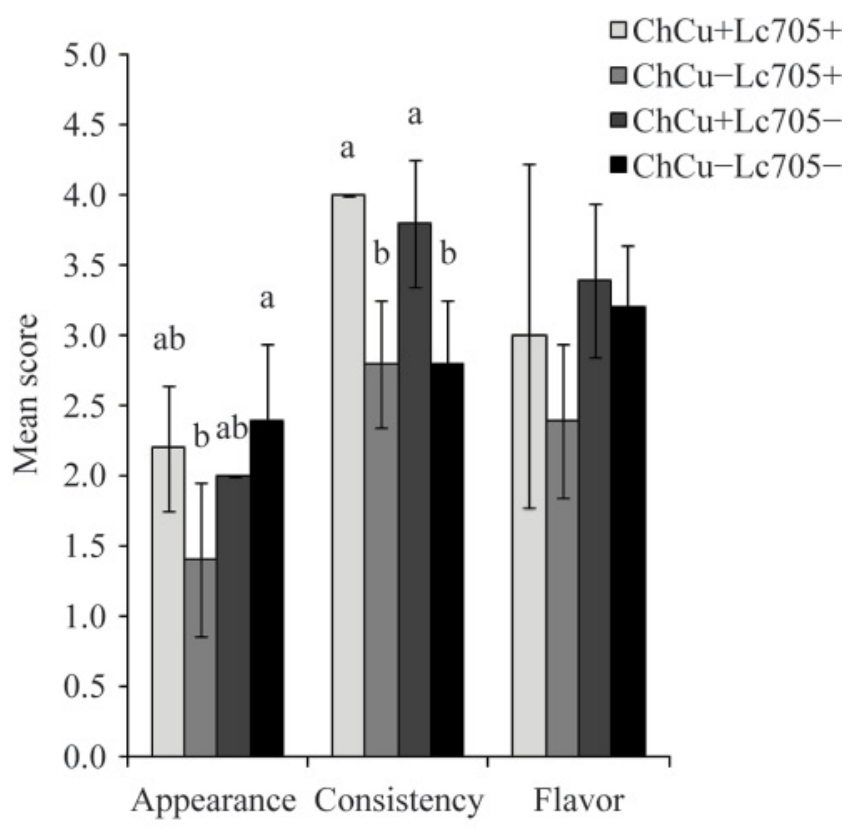

Figure 5. Results of sensory evaluation: (a) principal component analysis and (b) mean and standard deviations. $\mathrm{ChCu}+\mathrm{Lc} 705+=$ cheese produced with the addition of copper and the protective strain Lactobacillus rhamnosus Lc705 (Lc705); ChCu-Lc705+ = cheese produced without the addition of copper but with the addition of the protective strain Lc705; ChCu+Lc705- = cheese produced with the addition of copper but without the addition of the protective strain Lc705; and $\mathrm{ChCu}-\mathrm{Lc} 705-=$ cheese produced without addition of copper or the protective strain Lc705. Means with different letters differ significantly $(P<0.05)$. Color version available in the online PDF.

in this type of cheese because lysis in the different starter populations during cool-room ripening is more pronounced (Valence et al., 2000). Our results with the set of cheeses produced with $L b$. rhamnosus Lc705 are in agreement with this decline. de Man, Rogosa, and Sharpe agar is the most commonly used medium for cultivation and screening of Lactobacillus and, although it mostly enables enumeration of this group of starters under certain incubation conditions (Tharmaraj and Shah, 2003), it is also a nonselective medium.

As noted in the Results section, the $\mathrm{pH}$ value after pressing in cheeses produced with $\mathrm{Cu}$ was higher, especially in cheeses produced with $L b$. rhamnosus Lc705. We expected to observe more pronounced differences at the $\mathrm{d} 1$ sampling point based on the results of our previous experiments, in which the $\mathrm{pH}$ values corresponding to $\mathrm{Cu}$-positive cheeses were 2 decimal points higher than the $\mathrm{pH}$ of cheeses produced without $\mathrm{Cu}$ addition (unpublished data). The counting results in M17-L agar at this point (d 1) showed a difference of only $0.5 \log$ units (Figure 2a); this may suggest that the activity, rather than the viability, of Strep. thermophilus was affected by the presence of $\mathrm{Cu}$ at concentrations of approximately $15 \mathrm{mg} / \mathrm{kg}$. The influence of $\mathrm{Cu}$ on acid production by Strep. thermophilus has been reported previously by Mueller et al. (1952), who observed that titratable acidity decreased with increasing $\mathrm{Cu}$ concentrations ranging from 0 to $8 \mathrm{mg} / \mathrm{kg}$.

Although the results of plating counts in Na-lactate agar did not show differences in cheeses with different $\mathrm{Cu}$ contents (Figure 2d), the level of organic acids indicated that the presence of $\mathrm{Cu}$ markedly influenced propionic acid production and, to a lesser extent, acetic acid production (Figure 3c and d). The accumulation of lactic acid and especially pyruvic acid suggests that $\mathrm{Cu}$ has an inhibitory effect on the lactate metabolism of the strain of propionibacteria used in our Emmental production (Figure 3a and b). During growth of propionibacteria on lactate, the lactate is initially oxidized to pyruvate (Piveteau, 1999). The high levels of pyruvate after warm-room fermentation in cheeses produced with added $\mathrm{Cu}$ could be a result of excretion by the cells because of the accumulation of pyruvate to levels that may be toxic for the cell. This mechanism has been suggested as one mechanism used by $P$. freundereichii ssp. shermanii to regulate the intracellular pool of pyruvate in lactate metabolism (Deborde and Boyaval, 2000). Pyruvate accumulation inside the cell could occur because of the inhibition of catabolism of pyruvate to propionate, acetate, and $\mathrm{CO}_{2}$ at one or more steps. 
As described in the Results section, the presence of $\mathrm{Cu}$ did not appear to influence the propionate:acetate ratio. The quality of Emmental cheese can be related to the extent of propionic acid fermentation, not only in terms of the actual amounts of propionate, acetate, and $\mathrm{CO}_{2}$, but also in terms of their relative proportions. In Swiss-type cheese, the theoretical equation (3 lactate $\rightarrow 2$ propionate +1 acetate $+1 \mathrm{CO}_{2}+1 \mathrm{H}_{2} \mathrm{O}$ ), which resulted from the formulation of Fitz (Boyaval and Core, 1995), is rarely found, and the relative product concentrations may vary significantly (Piveteau, 1999). The propionate:acetate ratio in commercial Finnish Emmental was reported to be approximately 1:0.7 (Pillonel et al., 2002). This value is in agreement with those obtained in this study (Figure $3 \mathrm{c}$ and d). Maurer et al. (1975) reported that added $\mathrm{Cu}$ in Emmental cheeses had no influence on acetic and propionic acid production. However, in the same study, the propionate:acetate ratio was $1: 1$ in most of the commercial cheeses but significantly higher in Iowa-style cheese, which differs from commercial ones by the fact that one-third of the whey is replaced by water during cheese-making.

The presence of added $\mathrm{Cu}$ increased the degree of proteolysis, as measured by $\mathrm{N}$ content in $\mathrm{pH} 4.4-\mathrm{SN}$ (Figure 4a). This fraction contained proteins (except intact caseins), all peptides, amino acids, and smaller $\mathrm{N}$ compounds such as amines, urea, and ammonium (IDF, 1999). Previous studies (Maurer et al., 1975) found that, in Swiss commercial cheeses, proteolysis was considerably higher in cheeses in which $\mathrm{Cu}$ was added to the milk compared with controls. However, because these authors were using the method reported by Vakaleris and Price (1959), our results obtained from the $\mathrm{pH}$ 4.4-SN fraction should be compared with caution. The opposite occurred when proteolysis was measured by the level of soluble $\mathrm{N}$ after fractionation with $5 \%$ phosphotungstic acid (Figure 4c). The N compounds found in this fraction are attributed to small peptides, amino acids, and smaller $\mathrm{N}$ compounds such as amines, urea, and ammonium (IDF, 1999). The presence of $\mathrm{Cu}$ appears to regulate secondary proteolysis; one explanation for these results could be the possible inhibition of certain peptidases from LAB and nonstarter LAB. The strong inhibition of aminopeptidase activities of Strep. thermophilus and Lb. delbrueckii ssp. bulgaricus in the presence of $\mathrm{Cu}^{2+}$ has been observed (Tsakalidou et al., 1993). One of the desired characteristics of $L b$. helveticus strains for the manufacture of cheeses is their high proteolytic activity; the activity of a tripeptidase from industrial $L b$. helveticus strain $53 / 7$ was completely inhibited by the presence of $\mathrm{Cu}$ (Savijoki and Palva, 2000).

The presence of $\mathrm{Cu}$ appeared to positively influence the sensory characteristics of the cheese produced un- der our conditions; both consistency and flavor received higher scores in cheese with added $\mathrm{Cu}$ compared with the cheeses without $\mathrm{Cu}$ (Figure 5). In particular, consistency was affected significantly. The texture of cheeses, which denotes consistency and structure of the cheese body, are closed related to the degree of primary proteolysis. Insufficient proteolysis may cause a flat taste and a longer body consistency that is usually described as rubbery. On the other hand, excessive proteolysis results in a sharp taste and shorter body (FröhlichWyder and Bachmann, 2004). The correlation between the degree of proteolysis, as measured by $\mathrm{pH} 4.4-\mathrm{SN}$ and TCA-SN (Figure 4a and b), and consistency in the cheeses supplemented with $\mathrm{Cu}$ (Figure 5a) suggests a positive role of the presence of $\mathrm{Cu}$ in our manufacturing conditions. The production of Emmental cheeses in $\mathrm{Cu}$ vats or the addition of $\mathrm{Cu}$ into the cheesemilk when stainless steel cheese vats are used is reported to have positive effects on cheese proteolysis (Sieber et al., 2006).

The role of the $L b$. rhamnosus Lc705 protective strain was not shown to have important effects on most of the parameters that influenced the final quality of the cheeses (Figure 5a). However, based on the enumeration results on MRS-vancomycin plates (Figure 2c), it is difficult to determine its role in this study. In any case, the addition of this strain had a negative effect on cheese appearance, mainly because of low eye formation when $\mathrm{Cu}$ was not added (Figure $5 \mathrm{a}$ ).

\section{CONCLUSIONS}

The addition of $\mathrm{Cu}$ to the cheesemilk at the levels used in Finland for industrial-scale production had some positive effects on the final quality of Emmental cheese. Although the traditional plating systems for enumerating bacterial populations during cheese manufacture did not reveal any drastic differences caused by the presence of $\mathrm{Cu}$, the chemical and sensory analyses suggest that utilization of $\mathrm{Cu}$ plays a significant role in regulation of bacterial physiological and biochemical activities, which in turn affect the sensory quality of Emmental cheese.

\section{ACKNOWLEDGMENTS}

The authors thank the Finnish Cultural Foundation (Helsinki) for partially supporting this research.

\section{REFERENCES}

Akalin, A., S. Gönc, and Y. Akbas. 2002. Variation in organic acids content during ripening of pickled white cheese. J. Dairy Sci. 85:1670-1676.

AOAC. 2000. Official Methods of Analysis. Vol. II. 17th ed. Association of Official Analytical Chemists International, Gaithersburg, MD. 
Baer, A., and I. Ryba. 1999. Interactions between propionic acid bacteria and thermophilic lactic acid bacteria. Lait 79:79-92.

Boyaval, P., and C. Core. 1995. Production of propionic acid. Lait $75: 453-461$.

Deborde, C., and P. Boyaval. 2000. Interactions between pyruvate and lactate metabolism in Propionibacerium freudenreichii ssp. shermani: In vivo ${ }^{13} \mathrm{C}$ nuclear magnetic resonance studies . Appl. Environ. Microbiol. 66:2012-2020.

Fröhlich-Wyder, M. T., and H. P. Bachmann. 2004. Cheeses with propionic acid fermentation. Pages 141-156 in Cheese: Chemistry, Physics and Microbiology, Vol. 2. P. F. Fox, P. L. H. McSweeney, T. M. Cogan, and T. P. Guinee, ed. Elsevier Academic Press, London, UK.

IDF. 1982. Reference Method. Cheese and processed cheese: Determination of the total solid content. Standard 4A. International Dairy Federation, Brussels, Belgium.

IDF. 1997. Reference Method. Sensory evaluation of dairy products by scoring. Standard 99C. International Dairy Federation, Brussels, Belgium.

IDF. 1999. Chemical methods for evaluating proteolysis in cheese maturation. IDF Bull. 33. International Dairy Federation, Brussels, Belgium.

ISO. 1975. Cheese: Determination of fat content by Van Gulik method. Standard 3433. International Standardisation Organization, Geneva, Switzerland.

Jimeno, J. 1997. Lactobacillus casei et Lactobacillus rhamnosus citrate (+) et citrate (-) des MK 3007 et 3008: Croissance et antagonisme dans l'emmental modèle. FAM Intern. Ber. Biochem. 14:1-18.

Jimeno, J., M. J. Lazaro, and H. Sollberger. 1995. Antagonistic interactions between propionibacteria and non starter lactic acid bacteria. Lait 75:401-413.

Johnson, M. E., and N. F. Olson. 1985. A comparison of available methods for determining salt levels in cheese. J. Dairy Sci. 68:1020-1024.

Kiermeier, F., H. Jäckl, and J. Hanusch. 1961. Über den Einfluss des Kesselmaterials auf die Eigenschaften von Emmentalerkäse. Z. Lebensm. Unters. Forsch. 115:493-505.

Kocaoglu-Vurma, N. A., W. J. Harper, M. A. Drake, and P. D. Courtney. 2008. Microbiological, chemical, and sensory characteristics of Swiss cheese manufactured with adjunct Lactobacillus strains. J. Dairy Sci. 91:2947-2959.

Kumpulainen, J., and M. Paakki. 1987. Analytical quality control used by the trace elements in food and diets sub-network of the FAO European cooperative network on trace elements. Fresenius J. Anal. Chem. 326:684-689.

Mato Rodríguez, L., and T. Alatossava. 2008. Effects of copper supplement on growth and viability of strains used as starters and adjunct cultures for Emmental cheese manufacture. J. Appl. Microbiol. 105:1098-1106.

Maurer, L., G. W. Reinbold, and E. G. Hammond. 1975. Effect of copper on microorganisms used in the manufacture of Swiss cheeses. J. Dairy Sci. 58:1630-1636.
Mueller, H. F., W. O. Nelson, and W. A. Wood. 1952. The effect of copper upon the activity of bacteria associated with Swiss cheese manufacture. J. Dairy Sci. 35:929-936.

Mullin, W., and D. Emmons. 1997. Determination of organic acids in cheese, milk and whey by high performance liquid chromatography. Food Res. Int. 30:147-151.

Perez Chaia, A., A. Pesce de Ruiz Holgado, and G. Oliver. 1987. Interactions between Lactobacillus helveticus and Propionibacterium freudenreichii ssp. shermanii. Microbiol. Aliment. Nutr. 5:325331.

Pillonel, L., R. Badertscher, U. Bütikofer, M. Casey, M. Dalla Torre, P. Lavanchy, J. Meyer, R. Tabacchi, and J. O. Bosset. 2002. Analytical methods for the determination of geographic origin of Emmentaler cheese. Main framework of the project: Chemical, biochemical, microbiological, colour and sensory analysis. Eur. Food Res. Technol. 215:260-267.

Pillonel, L., R. Badertscher, M. Casey, J. Meyer, A. Rossmann, H. Schlichtherle-Cerny, R. Tabacchi, and J. O. Bosset. 2005. Geographic origin of European Emmental. Use of discriminant analysis and artificial neural network for classification purposes. Int. Dairy J. 15:547-556.

Piveteau, P. 1999. Metabolism of lactate and sugars by dairy propionibacteria: A review. Lait 79:23-41.

Savijoki, K., and A. Palva. 2000. Purification and molecular characterization of a tripeptidase (Pep T) from Lactobacillus helveticus. Appl. Environ. Microbiol. 66:794-800.

Sieber, R., B. Rehberger, F. Schallet, and P. Gallman. 2006. Technological aspects of copper in milk products and health implications of copper. Agroscope Liebefeld-Posieux Sci. 493:1-15.

Tharmaraj, N., and N. P. Shah. 2003. Selective enumeration of Lactobacillus delbrueckii ssp. bulgaricus, Streptococcus thermophilus, Lactobacillus acidophilus, bifidobacteria, Lactobacillus casei, Lactobacillus rhamnosus, and propionibacteria. J. Dairy Sci 86:2288-2296.

Tsakalidou, E., I. Dalezious, M. Georgalaki, and G. Kalantzopoulos. 1993. A comparative study: Aminopeptidases activities from Lactobacillus delbrueckii ssp. bulgaricus and Streptococcus thermophilus. J. Dairy Sci. 76:2145-2151.

Tuomola, E. M., A. C. Ouwehand, and S. J. Salminen. 1999. Human ileostomy glycoproteins as a model for small intestinal mucus to investigate adhesion of probiotics. Lett. Appl. Microbiol. $28: 159-163$.

Vakaleris, D. G., and W. V. Price. 1959. A rapid spectrophotometric method for measuring cheese ripening. J. Dairy Sci. 42:264-276.

Valence, F., S. M. Deutsch, R. Richoux, V. Gagnaire, and S. Lortal. 2000. Autolysis and related proteolysis in Swiss cheese for two Lactobacillus helveticus strains. J. Dairy Res. 67:261-271. 